\title{
Physiotherapy practice of early mobilization in intensive care units of selected west Malaysian hospitals: a cross-sectional survey
}

\author{
DOI: https://doi.org/10.5114/pq.2020.89812
}

\author{
Lim Yuh Yean', Thirumalaya Balaraman', Narasimman Swaminathan² \\ ${ }^{1}$ Faculty of Health and Life Sciences, INTI International University, Nilai, Malaysia \\ ${ }^{2}$ Faculty of Allied Health Sciences, Sri Ramachandra Institute of Higher Education and Research, Chennai, India
}

\section{Abstract}

Introduction. Early mobilization (EM) in the intensive care unit (ICU) improves clinical outcomes. Despite the positive evidence, the implementation of EM is low in many countries. However, little is known about the practice of EM in ICU by physiotherapists in West Malaysia. Hence, this study was planned to assess the practice of physiotherapist-initiated EM in respiratory ICUs of selected West Malaysian hospitals.

Methods. A cross-sectional survey was conducted by using a self-administered questionnaire. The participants were registered physiotherapists with a minimum of 2 years working experience in respiratory ICUs, recruited from private or government hospitals with the convenience sampling method.

Results. Overall, 102 complete responses out of 200 were received. Most respondents stated that they practised EM in ICU, while $73.53 \%$ claimed that they mobilized patients with ventilator support. The majority indicated that they used a standard protocol to select patients for EM. The most common factors that influenced the physiotherapists' clinical decision to perform EM were patient's medical stability and safety concerns about EM.

Conclusions. Most physiotherapists in the selected West Malaysian hospitals stated that they practised EM in ICU. However, studies are required to assess the effectiveness and outcomes of the EM performed by physiotherapists in Malaysia.

Key words: early mobilization, intensive care unit, physiotherapist

\section{Introduction}

Prolonged immobilization has a deleterious effect on bone mineral density, muscle mass, and impairment of major body systems, especially in critically ill patients of intensive care units (ICU), leading to a neuromuscular dysfunction which is known as ICU-acquired weakness [1, 2]. ICU-acquired weakness increases the duration of ICU stay by prolonging the period of mechanical ventilation [3]. Early mobilization (EM) in ICU is proven to be effective in improving skeletal muscle function, which in turn reduces the time of mechanical ventilation in patients with respiratory disorders. EM is reported to decrease the ICU and hospital stay by improving functional capacity. It is also important to note that EM in critically ill patients raises their quality of life in the longer perspective. Safe and feasible, EM is recommended in the routine care of the critically ill in the developed countries [4-8].

The definition of EM varies widely in the literature [9]. Generally, EM involves in-bed and out-of-bed activities with or without a healthcare provider's assistance [9]. EM begins within 24-72 hours of ICU admission. The risk of EM is comparatively low when compared with its benefits. Reported adverse effect such as line removal, extubation, abnormal physiological responses, or need for alteration in the medical plan of care accounted for less than $5 \%[10,11]$.

The practice of EM in the clinical area is surprisingly low in many countries. A survey conducted among physicians and physiotherapists of Canada showed that $59.8 \%$ did not have sufficient knowledge or skills to mobilize mechanically ventilated patients [12]. A point prevalence study performed in the United States reported that only $32 \%$ of therapists provided mobilization in the specified time [13]. Similarly, studies from New Zealand, Australia, and Germany also revealed a low patient mobilization rate $[14,15]$. When the developed countries show a low patient mobilization rate, the issues in developing countries are different. EM practice in developing countries differs from that in developed countries. Physician referral is mandatory to decide on physiotherapist practice and EM in Nepal and India [16-18]. Out-of-bed mobilization was reported to be low in Brazil and Zimbabwe $[19,20]$.

The median bed occupancy rate in Malaysian ICUs in 2016 was $87.7 \%$ out of 660 beds of the Ministry of Health hospitals [21]. Respiratory disorders are among the top causes for ICU admissions in Malaysia [21]. As physiotherapists are important team members to perform EM in ICU patients with respiratory conditions, understanding physiotherapists' practice in ICU is crucial. A study among Malaysian nurses found that half of them mobilized their mechanically ventilated patients 3 or more times per shift using passive and active exercises [22]. However, the physiotherapists' practice of EM in Malaysian ICUs in subjects with respiratory diseases is not documented. Hence, this study aimed to assess the practice of EM in respiratory ICUs by physiotherapists of selected West Malaysian hospitals.

\section{Subjects and methods}

\section{Study design}

A cross-sectional survey was conducted by using a selfadministered questionnaire (see Appendix) through e-mail

Correspondence address: Thirumalaya Balaraman, Faculty of Health and Life Sciences, INTI International University, Persiaran Perdana BBN, Putra Nilai-71800, Nilai, Negeri Sembilan, Malaysia, e-mail: bthirumalaya@gmail.com 
and/or hard copy. The participants were physiotherapists with a minimum of 2 years working experience in respiratory ICUs of private or government hospitals. The convenience sampling method was applied to recruit the participants from various states of West Malaysia. The physiotherapists were identified through the Malaysian Physiotherapy Association members registry and through hospitals.

\section{Study tool}

A self-administered questionnaire (see Appendix) was developed by the investigators in English on the basis of a literature review. The content of the questionnaire was validated by 2 specialist physiotherapists working in respiratory ICUs. The items included in the questionnaire referred to demographic data, assessments carried out by physiotherapists in ICU, current treatment practices with adult respiratory patients in ICU, and rationale for their choices of treatment practice. The questionnaire items were recorded in opened-ended, Likert-type rating scales and predetermined ranked responses.

The questionnaire was either sent through e-mail or distributed to the participants directly between March and April 2018. A reminder was sent in the case of no response from a participant within 2 weeks. A researcher distributed the questionnaire directly to therapists during the Malaysian Physiotherapy Association $55^{\text {th }}$ annual general meeting and also approached physiotherapy departments of some selected hospitals in West Malaysia.

\section{Analysis}

The data were exported to Microsoft Excel 2013 from a Google Form, while the data from paper questionnaires were entered into Microsoft Excel 2013 and combined together for analysis. Descriptive analysis in the form of frequency distribution and percentage for each section of the questionnaire was reported. All items requiring nominal responses were given a numerical code, starting from 1 . The Likert score for question 10 was changed to code $1-5$, in accordance with the sequence of the responses of always, usually, sometimes, rarely, and never. For open-ended questions, the responses were grouped on the basis of the common theme and reported.

\section{Ethical approval}

The research related to human use has complied with all the relevant national regulations and institutional policies, has followed the tenets of the Declaration of Helsinki, and has been approved by the INTI International University research ethics committee (dated December 15, 2017).

\section{Informed consent}

Informed consent has been obtained from all individuals included in this study.

\section{Results}

A total of 200 questionnaires and e-mails were distributed and 115 responses received (response rate: $57.5 \%$ ), out of which 13 responses were excluded owing to incomplete information. Hence, 102 responses were included for analysis.

The majority of the physiotherapists were female (70.59\%), with 2-4 years of working experience in ICU. Even though the questionnaires were distributed to all the states of West Malaysia, no response was received from the states of $\mathrm{Pa}$ hang, Perak, Kelantan, Kedah, or Perlis. Figure 1 presents the state distribution of the participants. Overall, $50.98 \%$ of the respondents were undergraduate physiotherapists, followed by $41.18 \%$ of diploma holders; the remaining ones were master degree holders. Most subjects $(60.78 \%)$ worked in private hospital setting.

Among the 102 respondents, 92 (90.2\%) reported that they practised EM in ICU patients, while 10 (9.8\%) stated that they did not. Those who applied EM in ICU among respiratory patients presented different attitudes towards EM (Table 1). The parameters of EM as reported by the physiotherapists are summarized in Table 2.

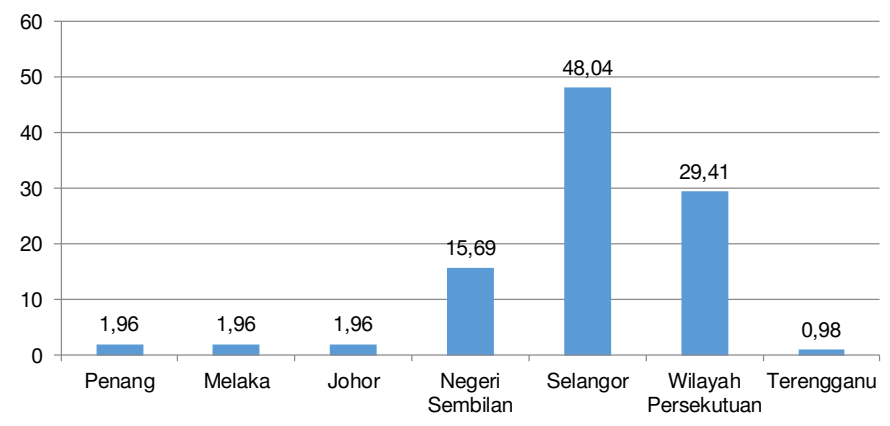

Figure 1. Percentage of respondents from various states of West Malaysia

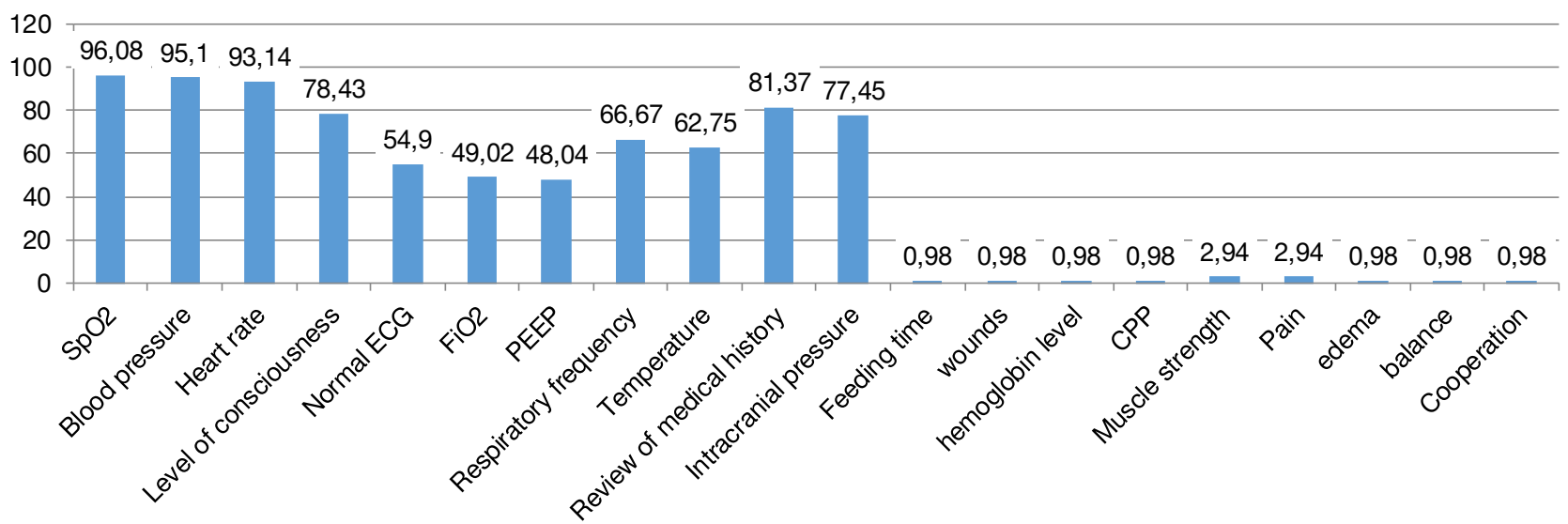

$\mathrm{SpO}_{2}$ - peripheral oxygen saturation, ECG - electrocardiography, $\mathrm{FiO}_{2}$ - fraction of inspired oxygen, PEEP - positive end-expiratory pressure, $\mathrm{CPP}$ - cerebral perfusion pressure

Figure 2. Criteria of eligibility for early mobilization 
Table 1. Practice and definition of EM

\begin{tabular}{|c|c|c|}
\hline EM practice & Count of respondents $(n=102)$ & Percentage (\%) \\
\hline Yes & 92 & 90.20 \\
\hline No & 10 & 9.80 \\
\hline EM definition & Count of respondents $(n=92)$ & Percentage (\%) \\
\hline $\begin{array}{l}\text { Start from passive range of motion, bed positioning, and slowly progress the } \\
\text { treatment plan to active exercise depending on the patient's condition as early } \\
\text { as possible }\end{array}$ & 29 & 31.52 \\
\hline $\begin{array}{l}\text { Involve the patient for active mobilization as early as possible and slowly } \\
\text { progress the treatment plan depending on the patient's condition }\end{array}$ & 32 & 34.78 \\
\hline $\begin{array}{l}\text { Involve the patient for active mobilization as early as possible and slowly } \\
\text { progress the treatment plan out of bed depending on the patient's condition }\end{array}$ & 14 & 15.22 \\
\hline To prevent future complications after ICU admission & 4 & 4.35 \\
\hline $\begin{array}{l}\text { Improve the patient's functional capacity and prevent prolonged bed-ridden } \\
\text { condition }\end{array}$ & 3 & 3.26 \\
\hline Bed mobility & 5 & 5.43 \\
\hline $\begin{array}{l}\text { Start from passive range of motion, bed positioning, and slowly progress } \\
\text { the treatment plan to active exercise and include chest physiotherapy } \\
\text { depending on the patient's condition as early as possible }\end{array}$ & 4 & 4.35 \\
\hline $\begin{array}{l}\text { Involve the patient for active mobilization as early as possible and slowly } \\
\text { progress the treatment plan depending on the patient's condition combined } \\
\text { with chest physiotherapy }\end{array}$ & 1 & 1.09 \\
\hline
\end{tabular}

EM - early mobilization, ICU - intensive care unit

Table 2. EM parameters

\begin{tabular}{|c|c|c|}
\hline EM practice based on day of ICU admission & Count of respondents $(n=102)$ & Percentage (\%) \\
\hline $1-2$ & 47 & 46.08 \\
\hline $2-5$ & 47 & 46.08 \\
\hline $6-8$ & 3 & 2.94 \\
\hline$>8$ & 2 & 1.96 \\
\hline Not specified & 3 & 2.94 \\
\hline Frequency & Count of respondents $(n=102)$ & Percentage (\%) \\
\hline 1 time in $>4$ days & 6 & 5.88 \\
\hline 1 time in 3 days & 1 & 0.98 \\
\hline 1 time in 2 days & 2 & 1.96 \\
\hline 1 time daily & 26 & 25.49 \\
\hline 2 times daily & 62 & 60.78 \\
\hline 3 times daily & 5 & 4.90 \\
\hline EM of patients with ventilator support & Count of respondents $(n=102)$ & Percentage (\%) \\
\hline Yes & 75 & 73.53 \\
\hline No & 27 & 26.47 \\
\hline
\end{tabular}

EM - early mobilization, ICU - intensive care unit

The criteria applied by physiotherapists in West Malaysia to decide on the patients' eligibility for EM are shown in Figure 2. The ICU EM parameters are summarized in Figure 3. Table 3 lists the factors that influenced the therapists' clinical decisions regarding EM. 
Table 3. Factors that influenced therapists' clinical decision on EM

\begin{tabular}{|c|c|c|}
\hline Factors & Count of respondents $(n=102)$ & Percentage (\%) \\
\hline Protocols or guidelines provided & 74 & 72.55 \\
\hline Equipment provided for EM & 60 & 58.82 \\
\hline Physical space & 46 & 45.10 \\
\hline Assistance from other staff & 66 & 64.71 \\
\hline Clinical experience in EM & 64 & 62.75 \\
\hline Knowledge or training about EM & 66 & 64.71 \\
\hline Safety concerns about EM & 83 & 81.37 \\
\hline Patient's medical stability & 86 & 84.31 \\
\hline Amount of sedation used in the patient & 53 & 51.96 \\
\hline Catheter location & 27 & 26.47 \\
\hline Patient body weight & 39 & 38.24 \\
\hline Cognitive level & 76 & 74.51 \\
\hline Endotracheal intubation & 40 & 39.22 \\
\hline Psychological status & 1 & 0.98 \\
\hline
\end{tabular}

EM - early mobilization

ICU EM parameters (\%)

$\square$ Assessment $\square$ Criteria to terminate PT $\square$ Outcome measure $\quad$ Type of exercises

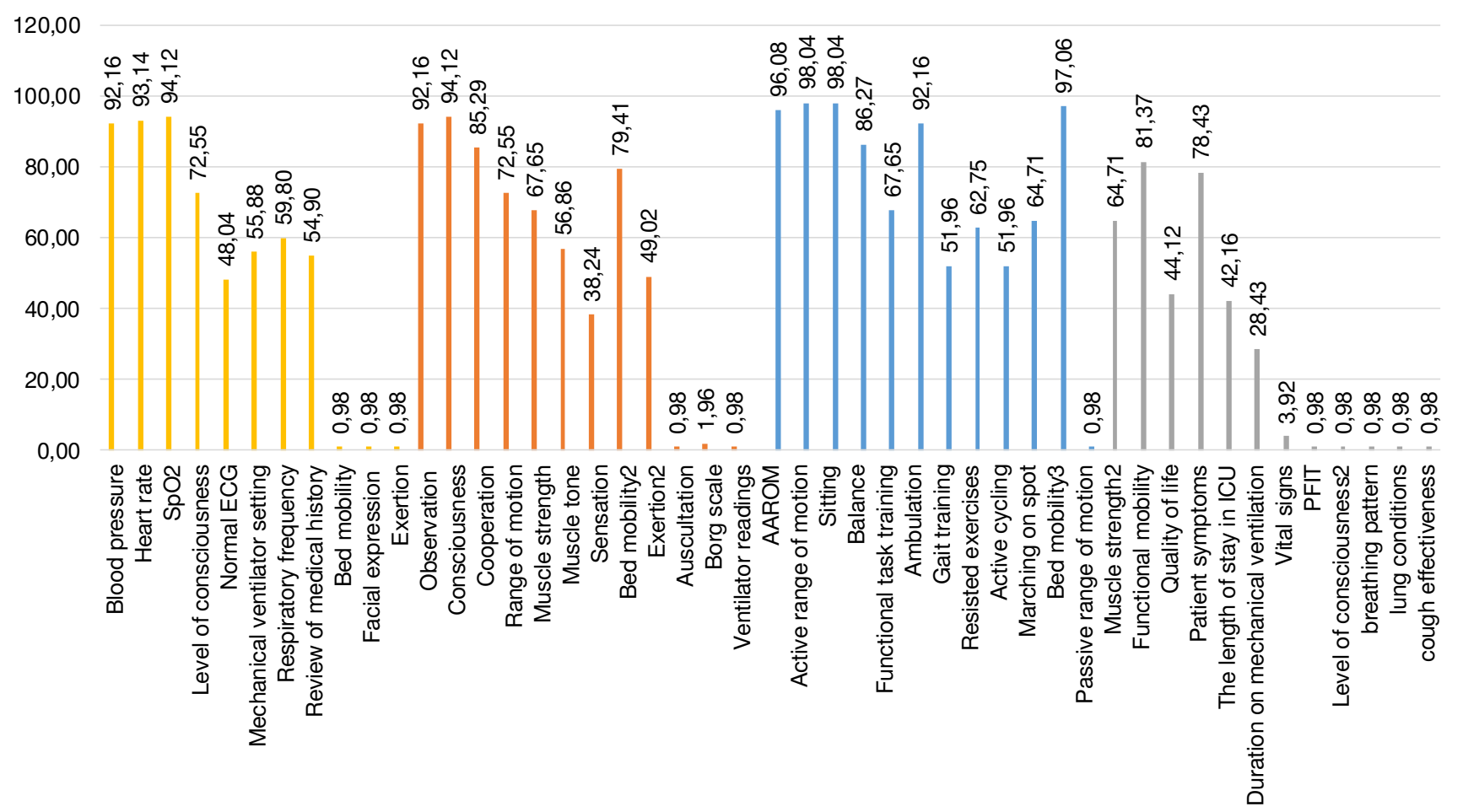

$\mathrm{PT}$ - physiotherapy, $\mathrm{SpO}_{2}$ - peripheral oxygen saturation, ECG - electrocardiography, AAROM - active assistive range of motion, PFIT - physical function intensive care unit test

Figure 3. Intensive care unit early mobilization parameters 


\section{Discussion}

To our knowledge, this is the first study in West Malaysia to assess the EM practice of physiotherapists in respiratory ICUs. Overall, $90.2 \%$ of the respondents reported that they practised EM in respiratory ICUs. When comparing these data with those from other developed and developing countries, the percentage seems to be high [12-20]. However, caution should be taken while interpreting the data. The data from developed countries are point prevalence study data which reflect the actual practice and also focus on out-of-bed mobilization. Nonetheless, there is a high possibility of response bias in this study as it involves data self-reported by physiotherapists. The definition of EM provided by physiotherapist is this study widely varies, from passive movements to out-of-bed mobility.

The Malaysian management protocols in ICU state that EM should be started 24-48 hours after ICU admission in the absence of contraindications. The program consists of progressive mobilization, with progression depending on a patient's functional capability and ability to tolerate the activity [23]. Nevertheless, only $46 \%$ of the respondents stated that they started the mobilization on the $1^{\text {st }}$ or $2^{\text {nd }}$ day. In Malaysia, physiotherapists depend on physicians' order to start EM and that could be a reason for the delay. However, the majority of physiotherapists provided EM twice daily, while the frequency in the literature is not clear [10].

Overall, $1 / 3$ of the participants stated that they mobilized patients with ventilator support, which is a higher rate than that reported in the literature from developed countries $[13,24]$. On the other hand, these data should be interpreted with caution, considering the meaning of EM in ICU and the response bias.

Most physiotherapists chose peripheral oxygen saturation $\left(\mathrm{SpO}_{2}\right)$, blood pressure, heart rate, level of consciousness, review of medical history, and intracranial pressure as the eligibility criteria for EM, which is accordance with the reports from the previous systematic reviews and guidelines $[6,23$, 25-28]. Contrarily, slightly more than half of the respondents selected positive end-expiratory pressure (PEEP), fraction of inspired oxygen $\left(\mathrm{FiO}_{2}\right)$, electrocardiography (ECG), respiratory frequency, and temperature, which are very important criteria as per the guidelines [6, 23, 25-28]. Besides, physiotherapists only mobilized the patients under a physician's order as required for physiotherapy in Malaysia [29]. Hence, they might not know about certain factors as the decision is always on the part of the physician. More than $80 \%$ of the respondents chose the evidence-based range for eligibility criteria of EM provided in the questionnaires except for the heart rate, where only $77.89 \%$ selected the given range. Some subjects mentioned that they used the Glasgow Coma Scale instead of the Richmond Agitation-Sedation Scale, which is also supported by the literature [30].

For the criteria to terminate an EM session, most respondents chose important vital parameters like blood pressure $[11,23]$. Nonetheless, less than $60 \%$ would take ECG, mechanical ventilator setting, respiratory frequency, and review of medical history into consideration to terminate their mobilization sessions. This may be unsafe as these are important parameters to prevent adverse events.

Consciousness, observation, cooperation, range of motion, and muscle strength were assessments performed by most physiotherapists before EM, which is in accordance with the available evidence and guidelines [25]. The foremost outcome measures used by physiotherapists in West Malaysia were functional mobility, patient symptoms, and muscle strength, which is consistent with the literature reported [11]. Conversely, less than half of the participants chose quality of life and the length of ICU stay as their outcome measures, which are also important as per the reported literature $[8,11]$.

More than $90 \%$ of the physiotherapists claimed that they would perform active and active assisted range of motion, sitting, bed mobility, and ambulation in their practice of EM, which is higher than the reported values from developed and other developing countries [13, 16, 19, 20, 24]. Active cycling, which is widely implemented in ICU, is not commonly carried out in Malaysia [9]. It could be due to the limited equipment availability in West Malaysia ICUs as more than half of the physiotherapists stated that as the factor that affected their clinical decisions to perform EM. Besides, less practice of ambulation, marching on spot, resisted exercise, and active cycling may be attributed to patients' medical instability, the physiotherapists' experience and education as most of the physiotherapists in this survey were with 2-4 years of experience in ICU with diploma qualification. Also, this research particularly focused on respiratory patients whereas most studies assessed EM in ICU irrespective of diagnosis; this could be a reason for variation in practices.

Patients' medical stability, safety concerns about EM, cognitive level, and protocols or guidelines provided were the most reported factors influencing physiotherapists' clinical decisions on EM. Similarly, a survey from Canada reported that patient medical stability and no written guidelines or protocols were the major barrier to EM [12]. Even though Kementerian Kesihatan Malaysia and Malaysian Society of Intensive Care published a protocol on ICU patients management, its availability and knowledge among physiotherapists is not clear and there has been no update in the protocol since it was released in 2012 [23]. However, most of the physiotherapists' practice relates to the protocol. Also, private hospitals may follow different guidelines as per their hospital policy, which may also influence the physiotherapists' EM practice.

\section{Limitations}

The main limitation of this research is the small sample size and unproportioned samples from each state of West Malaysia. The respondents were mainly from Selangor, Wilayah Persekutuan, and Negeri Sembilan, as time and funding were the major limitation to reach all the states personally. Hence, this survey result might not reflect the practice of EM in the entire West Malaysia. Even though the questionnaire presents details like ranges for each factor, the ranges were not discussed in the paper. A further point prevalence study to assess the EM implementation in ICU may give a better understanding of West Malaysian practice. Also, studies to assess the knowledge, perception, and barriers of EM in ICUs have to be carried out to address the difficulties in providing EM in West Malaysia.

\section{Conclusions}

Most physiotherapists in the selected West Malaysian hospitals practise EM in ICUs for respiratory patients. However, there is a wide variation in their practice. Hence, further studies are required to assess the effectiveness, clinical reasoning behind the decisions, and outcomes of EM performed by physiotherapists in Malaysia. 


\section{Disclosure statement}

No author has any financial interest or received any financial benefit from this research.

\section{Conflict of interest}

The authors state no conflict of interest.

\section{References}

1. Parry SM, Puthucheary ZA. The impact of extended bed rest on the musculoskeletal system in the critical care environment. Extrem Physiol Med. 2015;4:16; doi: 10.1186/s13728-015-0036-7.

2. Truong AD, Fan E, Brower RG, Needham DM. Bench-tobedside review: mobilizing patients in the intensive care unit - from pathophysiology to clinical trials. Crit Care. 2009;13(4):216; doi: 10.1186/cc7885.

3. Appleton R, Kinsella J. Intensive care unit-acquired weakness. Contin Educ Anaesth Crit Care Pain. 2012;12(2): 62-66; doi: 10.1093/bjaceaccp/mkr057.

4. Arias-Fernández P, Romero-Martin M, Gómez-Salgado J, Fernández-García D. Rehabilitation and early mobilization in the critical patient: systematic review. J Phys Ther Sci. 2018;30(9):1193-1201; doi: 10.1589/jpts.30. 1193.

5. Castro-Avila AC, Serón P, Fan E, Gaete M, Mickan S. Effect of early rehabilitation during intensive care unit stay on functional status: systematic review and metaanalysis. PLoS One. 2015;10(7):e0130722; doi: 10.1371/ journal.pone.0130722.

6. Hodgson CL, Capell E, Tipping CJ. Early mobilization of patients in intensive care: organization, communication and safety factors that influence translation into clinical practice. Crit Care. 2018;22(1):77; doi: 10.1186/ s13054-018-1998-9.

7. Yue M, Ma Z-Y, Lei M-J, Cui C-Y, Jin Y. Early mobilization for mechanically ventilated patients in the intensive care unit: a systematic review and meta-analysis. Front Nurs. 2018;5(4):301-310; doi: 10.1515/fon-2018-0039.

8. Kayambu G, Boots R, Paratz J. Physical therapy for the critically ill in the ICU: a systematic review and metaanalysis. Crit Care Med. 2013;41(6):1543-1554; doi: 10.1097/CCM.0b013e31827ca637.

9. Clarissa C, Salisbury L, Rodgers S, Kean S. Early mobilisation in mechanically ventilated patients: a systematic integrative review of definitions and activities. J Intensive Care. 2019;7:3; doi: 10.1186/s40560-018-0355-z.

10. Taito S, Shime N, Ota K, Yasuda H. Early mobilization of mechanically ventilated patients in the intensive care unit. J Intensive Care. 2016;4:50; doi: 10.1186/s40560-0160179-7.

11. Adler J, Malone D. Early mobilization in the intensive care unit: a systematic review. Cardiopulm Phys Ther J. 2012; 23(1):5-13; doi: 10.1097/01823246-201223010-00002.

12. Koo KKY, Choong K, Cook DJ, Herridge M, Newman A, Lo V, et al. Early mobilization of critically ill adults: a survey of knowledge, perceptions and practices of Canadian physicians and physiotherapists. CMAJ Open. 2016;4(3): E448-E454; doi: 10.9778/cmajo.20160021.

13. Jolley SE, Moss M, Needham DM, Caldwell E, Morris PE, Miller RR, et al. Point prevalence study of mobilization practices for acute respiratory failure patients in the United States. Crit Care Med. 2017;45(2):205-215; doi: 10.1097/CCM.0000000000002058.

14. Berney SC, Harrold M, Webb SA, Seppelt I, Patman S, Thomas PJ, et al. Intensive care unit mobility practices in Australia and New Zealand: a point prevalence study. Crit Care Resusc. 2013;15(4):260-265.
15. Nydahl P, Ruhl AP, Bartoszek G, Dubb R, Filipovic S, Flohr $\mathrm{H}$-J, et al. Early mobilization of mechanically ventilated patients: a 1-day point-prevalence study in Germany. Crit Care Med. 2014;42(5):1178-1186; doi: 10.1097/CCM.0000000000000149.

16. Baidya S, Acharya RS, Coppieters MW. Physiotherapy practice patterns in intensive care units of Nepal: a multicenter survey. Indian J Crit Care Med. 2016;20(2):8490; doi: 10.4103/0972-5229.175939.

17. Kumar JA, Maiya AG, Pereira D. Role of physiotherapists in intensive care units of India: a multicenter survey. Indian J Crit Care Med. 2007;11(4):198-203; doi: 10.4103/09725229.37715.

18. Yeole UL, Chand AR, Nandi BB, Gawali PP, Adkitte RG. Physiotherapy practices in intensive care units across Maharashtra. Indian J Crit Care Med. 2015;19(11):669673; doi: 10.4103/0972-5229.169346.

19. Fontela PC, Lisboa TC, Forgiarini-Júnior LA, Friedman G. Early mobilization practices of mechanically ventilated patients: a 1-day point-prevalence study in southern Brazil. Clinics. 2018;73:e241; doi: 10.6061/clinics/2018/e241.

20. Tadyanemhandu C, van Aswegen H, Ntsiea V. Early mobilisation practices of patients in intensive care units in Zimbabwean government hospitals - a cross-sectional study. South Afr J Crit Care. 2018;34(1):16-21; doi: 10.7196/sajcc.2017.v34i1.343.

21. Ling TL, Har LC, Nor MRBM, Ismail NIB, Ismail WNBW. Malaysian Registry of Intensive Care 2016 report. Malaysian Registry of Intensive Care; 2017. Available from: https://www.crc.gov.my/wp-content/uploads/documents/report/mric_report_2016.pdf.

22. Leong YL, Rasnah AR, Chong MC. Patient early mobilization: a Malaysia's study of nursing practices. J Intensive Crit Care.2017;3(3):29; doi:10.21767/2471-8505.100088.

23. Anaesthesia Programme, Kementerian Kesihatan Malaysia, Malaysian Society of Intensive Care. Management protocols in ICU. 2012.

24. Harrold ME, Salisbury LG, Webb SA, Allison GT, Australia and Scotland ICU Physiotherapy Collaboration. Early mobilisation in intensive care units in Australia and Scotland: a prospective, observational cohort study examining mobilisation practises and barriers. Crit Care. 2015;19:336; doi: 10.1186/s13054-015-1033-3.

25. Berry A, Beattie K, Bennett J, Chaseling W, Cross Y, Cushway S, et al. Physical activity and movement: a guideline for critically ill adults, $2^{\text {nd }}$ ed. Agency for Clinical Innovation; 2017.

26. Sommers J, Engelbert RH, Dettling-Ihnenfeldt D, Gosselink R, Spronk PE, Nollet F, et al. Physiotherapy in the intensive care unit: an evidence-based, expert driven, practical statement and rehabilitation recommendations. Clin Rehabil. 2015;29(11):1051-1063; doi: 10.1177/ 0269215514567156.

27. Da Conceição TMA, Gonzáles AI, de Figueiredo FCXS, Vieira DSR, Bündchen DC. Safety criteria to start early mobilization in intensive care units. Systematic review. Rev Bras Ter Intensiva. 2017;29(4):509-519; doi: 10.5935/ 0103-507X.20170076.

28. Hodgson CL, Stiller K, Needham DM, Tipping CJ, Harrold $\mathrm{M}$, Baldwin $\mathrm{CE}$, et al. Expert consensus and recommendations on safety criteria for active mobilization of mechanically ventilated critically ill adults. Crit Care. 2014;18(6):658; doi: 10.1186/s13054-014-0658-y.

29. World Confederation for Physical Therapy. Malaysia: a profile of the profession. Available from: https://www. wcpt.org/node/150110/cds. 
30. Hickmann CE, Castanares-Zapatero D, Bialais E, Dugernier J, Tordeur A, Colmant L, et al. Teamwork enables high level of early mobilization in critically ill patients. Ann Intensive Care. 2016;6(1):80; doi: 10.1186/s13613016-0184-y.

\section{Appendix}

\section{Questionnaire}

Demographic data

1. Age:

2. Gender:

$\square$ Male

$\square$ Female

3. Working experience in adult ICU with respiratory

disease patients:

$\square$ Less than 2 years

$\square 2-4$ years

$\square 5-7$ years

$\square$ 8-10 years

$\square$ More than 10 years

4. Qualification level:
$\square$ Diploma
$\square$ Undergraduate
$\square$ Master

$\square$ Doctor level

Other:

5. In what hospital setting do you work now?

$\square$ Private

$\square$ Government

6. Which state do you work in?

$\square$ Johor

$\square$ Melaka

$\square$ Negeri Sembilan

$\square$ Selangor

$\square$ Pahang

$\square$ Penang

$\square$ Perak

$\square$ Kedah

$\square$ Kelantan

$\square$ Perlis

$\square$ Terengganu

Practice pattern of early mobilization in respiratory disease patients in intensive care unit

1. Do you practise early mobilization in ICU?

$\square$ Yes

$\square$ No

2. If yes, what do you mean by early mobilization?

3. When will you usually start early mobilization

in respiratory disease patients depending on their

day of admission?

$\square 1^{\text {st }}-2^{\text {nd }}$

$\square 2^{\text {nd }}-5^{\text {th }}$

$\square 6^{\text {th }}-8^{\text {th }}$

$\square$ After 8 days

4. How often will you treat the patients in ICU?

$\square 1$ time in more than 4 days

$\square 1$ time in 3 days

$\square 1$ time in 2 days

$\square 1$ time daily

$\square 2$ times daily

$\square 3$ times daily

$\square$ Other:

5. Select the respiratory disease conditions with which you practise early mobilization in ICU. (Please tick the boxes below, you can choose more than one option)

$\square$ COPD

$\square$ Pleural effusion $\square$ Asthma

$\square$ Respiratory failure

$\square$ Other:

6. On the basis of which criteria do you decide on the patients' eligibility for early mobilization and what are the ranges? (Please tick the boxes below, you can choose more than one option. Please write the range if it differs from the criteria below)

Factors

$\square$ Blood pressure $\quad \square$ Criteria: mean arterial pressure: 60-110 mm Hg

$\square$ Heart rate
$\square \mathrm{SpO}_{2}$
$\square$ Level of
consciousness
$\square$ Normal ECG
$\square \mathrm{FiO}_{2}$

$\square$ Criteria: $40-130$ beats/min

$\square$ Criteria: $40-130$ beats/min

$\square$ Criteria: $\mathrm{SpO}_{2}>88 \%$ or $\mathrm{SpO}_{2}>90 \%$ with $4 \%$ oscillation

$\square$.................................

$\square$ Criteria: Richmond Agitation-Sedation Scale (RASS) score: $-4,-5,3,4$

Scale (RASS) score: -4,

$\square$ Criteria: without evidence of heart attack or arrhythmia

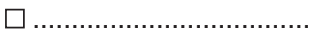

$\square$ PEEP

$\square$ Criteria: $<0.6$

$\square$ Respiratory frequency

$\square$ Criteria: $<10 \mathrm{~cm} \mathrm{H}_{2} \mathrm{O}$

$\square$ Temperature

$\square$ Criteria: < 40 breaths/min

\section{Criteria: $36-38.5^{\circ}$}

$\square$ Review of medical history

\section{$\square$ Criteria: no recent complications or} changes in cardiovascular or respiratory system and medication taken does not affect mobilization

$\square$ Intracranial pressure

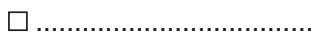

$\square$ Criteria: $<20 \mathrm{~cm} \mathrm{H}_{2} \mathrm{O}$

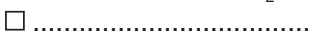

$\square$ Other:

7. On the basis of which criteria you decide to terminate a physiotherapy mobilization session? (Please tick the boxes below, you can choose more than one option. Please write the range if it differs from the criteria below)

\section{Factors \\ $\square$ Blood pressure}

$\square$ Heart rate

$\square \mathrm{SpO}_{2}$
Range

$\square$ Criteria:

$\square \mathrm{SBP}>180 \mathrm{~mm} \mathrm{Hg}$

$\square>20 \%$ decrease in SPB/DBP; orthostatic hypotension $\square \mathrm{MAP}<65 \mathrm{~mm} \mathrm{Hg} ;>110 \mathrm{~mm} \mathrm{Hg}$

Criteria:

$\square>70 \%$ APMHR

$\square>20 \%$ decrease in resting $\mathrm{HR}$

$\square<40$ beats/min; $>130$ beats/min

$\square$..............

$\square>4 \%$ decrease

$\square<88-90 \%$ 
$\square$ Level of consciousness $\square$

Criteria:

$\square$ Patient sedation or coma: RASS $\leq-3$

$\square$ Patient agitation requiring addition

or escalation of sedative medication:

RASS $>2$

$\square$ Patient c/o intolerable DOE

$\square$ Normal ECG

$\square$ Patient refusal

\begin{tabular}{|c|c|}
\hline \multirow{7}{*}{$\square$ Mechanical ventilator } & Criteria: \\
\hline & $\square$ New onset dysrhythmia \\
\hline & $\begin{array}{l}\square \\
\text { Criteria: }\end{array}$ \\
\hline & $\square \mathrm{FiO}_{2} \geq 0.60$ \\
\hline & $\square$ PEEP $\geq 10$ \\
\hline & $\square$ Patient-ventilator asynchrony \\
\hline & $\begin{array}{l}\square \mathrm{MV} \text { mode change to assist-control } \\
\square \text { Tenuous airway }\end{array}$ \\
\hline$\square$ Respiratory frequency & 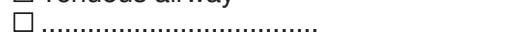 \\
\hline & Criteria: \\
\hline & $\square 5$ breaths/min; > 40 breaths $/ \mathrm{min}$ \\
\hline $\begin{array}{l}\square \text { Review of medical } \\
\text { history }\end{array}$ & 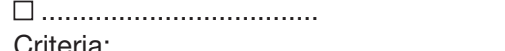 \\
\hline & $\square$ New anti-arrhythmia medication \\
\hline & $\square$ New cardiac enzymes \\
\hline & $\begin{array}{l}\square \text { Presence of vasopressor medication; } \\
\text { new vasopressor or escalating dose of } \\
\text { vasopressor medication }\end{array}$ \\
\hline
\end{tabular}

8. Do you mobilize patients with ventilator support?

$\square$ Yes

$\square$ No

9. What type of assessment will you carry out in ICU patients before mobilization? (Please tick the boxes below, you can choose more than one option)

$\square$ Observation (oedema, muscle atrophy, contracture, deformities, bed sores, decubitus, wound)

$\square$ Consciousness

$\square$ Cooperation

$\square$ Range of motion

$\square$ Muscle strength

$\square$ Muscle tone

$\square$ Sensation

$\square$ Bed mobility

$\square$ Exertion

$\square$ Other:

10. In your practice, early mobilization in ICU in respiratory disease patients involves: (Please tick the boxes below, you can choose more than one option. Please tick the frequency of the exercises involved in your practice)

Exercise

Always Usually Some- Rarely Never times
11. Please state the frequency, intensity, duration and type of early mobilization exercises that you practise, on the basis of the exercises that you selected in the question above (Please tick the boxes below, you can choose more than one option)

Exercise

Frequency Intensity Duration Type (if applicable)

$\square$ AAROM

$\square$ AROM

$\square$ Sitting

$\square$ Balance

$\square$ Functional task training

$\square$ Ambulation

$\square$ Gait training

$\square$ Active cycling

$\square$ Resisted exercises

$\square$ Bed mobility

$\square$ Marching on spot

$\square$ Other:

12. What are the outcome measures you record after the treatment? (Please tick the boxes below, you can choose more than one option)

$\square$ Muscle strength

$\square$ Functional mobility

$\square$ Quality of life

$\square$ Patient symptoms

$\square$ The length of ICU stay

$\square$ Duration of mechanical ventilation

$\square$ Other:

13. What are the factors that influence your clinical decision to perform early mobilization? (Please tick the boxes below, you can choose more than one option)

$\square$ Protocols or guidelines provided

$\square$ Equipment provided for early mobilization

$\square$ Physical space

$\square$ Assistance from other staff

$\square$ Clinical experience in early mobilization

$\square$ Knowledge or training about early mobilization

$\square$ Safety concerns about early mobilization

$\square$ Patient's medical stability

$\square$ Amount of sedation used in the patient

$\square$ Catheter location

$\square$ Patient body weight

$\square$ Cognitive level

$\square$ Endotracheal intubation

$\square$ Other:

The end

Thank you for participating in this survey!

$\square$ AAROM

$\square$ AROM

$\square$ Sitting

$\square$ Balance

$\square$ Functional task training

$\square$ Ambulation

$\square$ Gait training

$\square$ Active cycling

$\square$ Resisted exercises

$\square$ Bed mobility

$\square$ Marching on spot

$\square$ Other: 